\title{
Digital Renaissance: The Creative Potential of Narrative Technology in Education
}

\author{
Tony Hall \\ School of Education, National University of Ireland, Galway, Ireland \\ Email: tony.hall@nuigalway.ie
}

Received November $12^{\text {th }}, 2011$; revised December $10^{\text {th }}$, 2011; accepted December $26^{\text {th }}$, 2011

\begin{abstract}
This paper outlines research which explores the potential of narrative technology: the synergy of storytelling and computing to enhance creativity and creative education. The paper outlines the theoretical basis of the research: nöogenic narrative, which is informed by contemporary debates and themes in the educational sciences. These include narrativity and storytelling in education; and positive and humanistic psychology. Furthermore, from an empirical/practical perspective, a number of examples of narrative technology are presented and discussed. These exemplify the principal ways in which narrative technology has been deployed in the research-enhanced teaching outlined in this paper: as both a pedagogical, and as a reflective methodology. The paper concludes with insights regarding the deployment of narrative technology to enhance creativity and creative education; and how the synergy of storytelling and computing is potentially affording new possibilities for a digital renaissance in education and educational technology.
\end{abstract}

Keywords: Creativity; Education; Narrative; Storytelling; Educational Technology

\section{Introduction}

\section{Narrative: The Big Story in Education?}

In Against Narrativity (2004), Strawson critiques and refutes what he defines as the two key aspects of the prevailing narratological view in education. Firstly, he argues against the "psychological Narrativity thesis": the view that narrative is the principal means by which people live in, and make sense of their world. Secondly, he problematises and refutes the 'ethical Narrativity thesis', the normative position that narrative is essential to leading an ethical and productive existence: the "good life". Although such important critical insights are emerging from contradistinct positions in relation to narratology in education, pointing to potential limitations of narrative and storytelling in human experience and ontogenetic development, narrative is considered a foundational and powerful mediating tool in the development of human understanding, culture and society. Bruner (2007) would go as far as to contend: "There is no culture in the world without stories.” Schank (1990: p. 16) defines human intelligence by its relation to narrative: "All we have are experiences-but all we can effectively tell others are stories. Knowledge is experiences and stories, and intelligence is the apt use of experience and the creation and telling of stories”. For Bruner, narrative and storytelling are so innately a part of human experience that we are born to structure the world narratologically_in story-form; to the extent that it formatively and intrinsiccally shapes our nascent literacy: "one of the most ubiquitous and powerful discourse forms in human communication is narrative. Narrative structure is even inherent in the praxis of social interaction before it achieves linguistic expression; it is a 'push' to construct narrative that determines the order of priority in which grammatical forms are mastered by the young child" (1990: p. 77). As will be presently outlined, in recent years, technology has emerged that potentially creates new possibilities for narrativity, creativity and creative education. The re- search reported in this paper aims to explore innovative possibilities for education by combining potentially powerful human story-telling processes and new and emerging ICTs (information and communications technologies). How might the synergy of storytelling and computing - what we define as narrative technology - create new potential for creative education? The research reported in this paper endeavours to address this question; informed and inspired by a conception of education predicated on meaning, narrative and positive orientation.

\section{Nöogenic Narrative}

\section{Accomplishment, Affect and Attitude}

The conceptual approach that has emerged in our research into creative education, narrative and technology over the last five years is what we call the concept of nöogenic narrative, or the meaningful life story. According to Bruner (2007), life itself is autobiographical — we are each the protagonist, the main character in our own, ontogenetic narrative.

If we construe or see life as a story or narrative- - with different characters, themes, dramatic tensions, dénouements, emplotments and so forth - then what is the meaning of that story? Informed by key debates and themes in educational philosophy and psychology, nöogenic narrative endeavours to address this fundamental educational question. The concept of nöogenic narrative is inspired by positive psychology, principally Frankl (1946/ 2006) and Seligman (2011). According to the positive psychological approach, positivity or positive orientation (particularly in the face of life's unavoidable challenges and problems) is a crucial, determining factor in leading a meaningful, purposeful life.

In the seminal Man’s Search for Meaning (1946/2006), Frankl outlines three ways in which we can find meaning and purpose in life: 1) through accomplishment/achievement-by completing a task or doing a deed; 2) through recognising another person's or other people's unique potential and helping them to rea- 
lise that potential; and 3) through the attitude we take toward unavoidable suffering. According to Frankl, nöogenic neuroses (or crises of meaning) arise when there is an ostensible, existential vacuum or meaningless in life. Frankl contends however that meaning is always there, even when such crises arise-meaning is omnipresent in our lives; the challenge is to see it and appreciate its significance.

According to Frankl, life inevitably will have its painful, troubling and disappointing moments. However, our unique gift is to choose our attitude to unavoidable loss or pain; and to realise that even when times are tough, there is meaning to be found in life. The positive psychological approach has been further defined and extended in the contemporary context by Seligman through, for example, his PERMA model (2011), which identifies key fundaments of "Authentic Happiness" and the "good life”: (P)ositive Emotion, (E)ngagement, (R)elationships, (M)eaning and (A)chievement.

The concept of the nöogenic narrative integrates and synthesises fundamental aspects of positive psychology with the narratological conception of education: that narrative and positiveinspirational stories in particular are centrally important in human ontogenetic development-in human communication, creativity, culture, ethics, imagination and self-identity (e.g. Bruner, 2002; 2007).

Essentially, nöogenic narrative (Figure 1) can be defined as the view that life — as a narrative/story — draws its meaning fundamentally from three interpenetrating - and mutually reinforcing - dimensions of positive engagement: our relationship with our world (accomplishment); our relationship with others (affect); and, critically, our relationship with ourselves (attitude).

As will be presently outlined, narrative and its synergy with technology: narrative technology creates potential and significant possibilities to enhance the ternary dimensions of nöogenic narrative: accomplishment, affect and attitude.

\section{Creativity, Narrativity and Technology}

In recent years, new technologies have emerged that create new possibilities for education, learning and pedagogy. Plowman and Stephen advert to the educational potential of novel

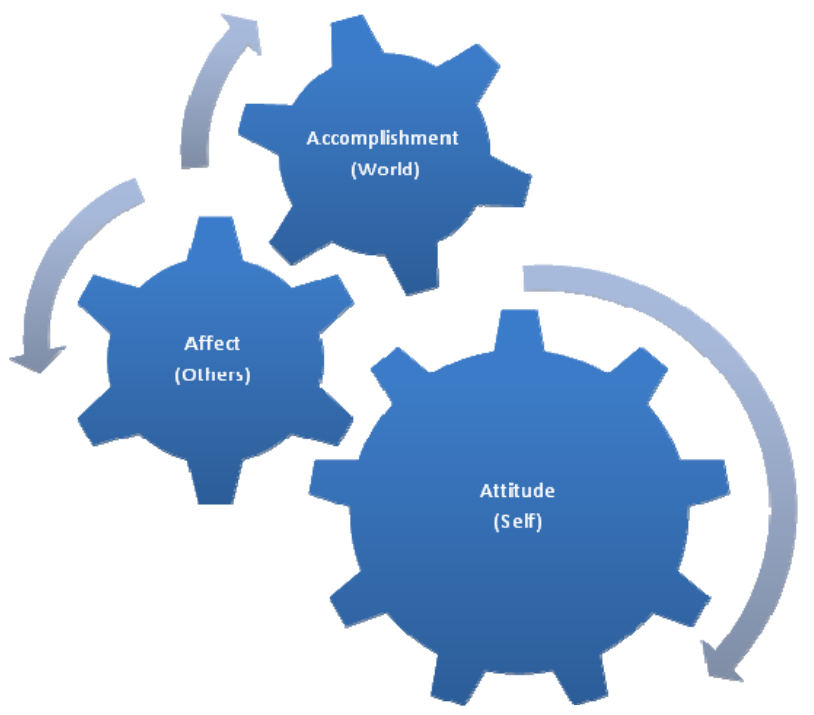

Figure 1.

Nöogenic narrative: dynamic dimensions of engagement. computing thus: "New technologies may lead to new concepts of play and learning in which ICT is much more than the "benign addition” referred to by Cuban (2001), especially as new ways are found of conceptualising ICT so that the term does not simply denote standard computers. These shifts in thinking may lead to technologies that can encompass participation by practitioners, parents and children in different learning spaces and promote discovery, delight, curiosity, creativity, self-expression and pleasure in learning” (2003: p. 160).

Our research aims to explore new potential and possibilities for education and pedagogy when intuitive, elegant and easyto-use technologies are combined with intrinsically powerful human forms of creativity, expressiveness and interpretation, principally narrative and storytelling. The emergence of new technology is potentially helping to realise new contexts, opportunities and resources for creativity and creative education (Futurelab, 2010). For example, just fifteen years ago, to digitise and edit video could usurp hours or even days of one's time. Now it is eminently easy to record video digitally with a mobile device and use an app on the device to edit, post-produce and share the video.

Although there have been very significant developments in respect of the interactive capabilities and usability of technology, reports such as the recently published EU Kids Online (2011) point to potential challenges and limitations in the way young people are conceptualising and using technology today.

EU Kids Online explodes a number of myths about children's and young people's contemporary use of technology, and the prevailing view that young people today are innately digitally literate: "Only 36 percent of 9 - 16-year-old say it is very true that they know more about the internet than their parents. This myth obscures children's needs to develop digital skills" (2011: p. 42). Furthermore, the report highlights limitations and passivity in the way young people are using computing, which predominantly focuses on ready-made content, and a "televisual" experience, which is particularly problematic for the development of creativity and creative education. The findings of research such as EU Kids Online (2011) serve to underscore the contemporary imperative to develop young people's digital competency and their digital creativity. But, how do we achieve these important twin aims of competency and creativity in young people's engagement with digital media? Furthermore, how do we support their teachers in developing their creativity and competency in ICT (Rizza, 2011), in ways that positively inform, shape and enhance their pedagogical practice and continuous professional development as educators in the $21^{\text {st }}$ Century? How can we utilise new, creative technologies to enhance nöogenic narrative along the three dynamic dimensions of engagement: accomplishment, affect and attitude?

\section{Narrative Technology in Education}

The paper outlines a number of explorations of ICT-designed, deployed, and evaluated over the last five years-which aimed to synergise narrative and technology to enhance learners' achievement and confidence, their intra- and inter-personal learning. Our use of narrative technology has encompassed different applications, and involved different groups of learners. Principally, there are two main ways in which we have deployed narrative technology in our research-enhanced teaching: 1) as a pedagogical methodology and 2) as a reflective methodology. 
The learner groups involved have included school children (primary and post-primary/second-level); older citizens and elderly members of the community; and teachers (in-service and pre-service).

Our interventions with narrative technology have focused on different learning outcomes, e.g. professional identity development; intercultural and intergenerational education; and enhancement of digital creativity, competency and literacy, across the curriculum.

Our evaluation of the design and deployment of narrative technology has been comprehensive, encompassing both direct feedback (anonymous and confidential) from learners; grouped pupil/student evaluations; and critical feedback from other stakeholders and independent assessment through external examination. The ICT artefacts, e.g. animations, digital narratives produced by learners have also served to illustrate the educational impact of learners' engagement with the narrative technology (Hall, Duignan \& Long, 2011).

\section{Narrative Technology for Pedagogy}

In ascribing importance to the power of storytelling in teaching, in the "Back to the Sagas" section of his seminal educational tract, Pearse went as far as to claim: "A heroic tale is more essentially a factor in education than a proposition in Euclid" (1916/2010). The first instantiation of narrative technology exemplified in this paper is the Living Scenes 3 (LS3) project. The goal of LS3 was to use the power of storytellingspecifically the heroic Irish tale of Fionn mac Cumhaill and the Fianna - to enhance intergenerational learning amongst student teachers; older, retired members of the community; and local schoolchildren. LS3 participants worked collaboratively-in intergenerational teams - on a large-scale group narrative: a modern re-telling of the story of Fionn mac Cumhaill and the Fianna. Facilitated by well-known local writers and artists, they developed their scripts into stop-frame animations, which re-imagined the story of Fionn, including a contemporary interpretation of this famous Irish narrative (Figures 2 and 3).

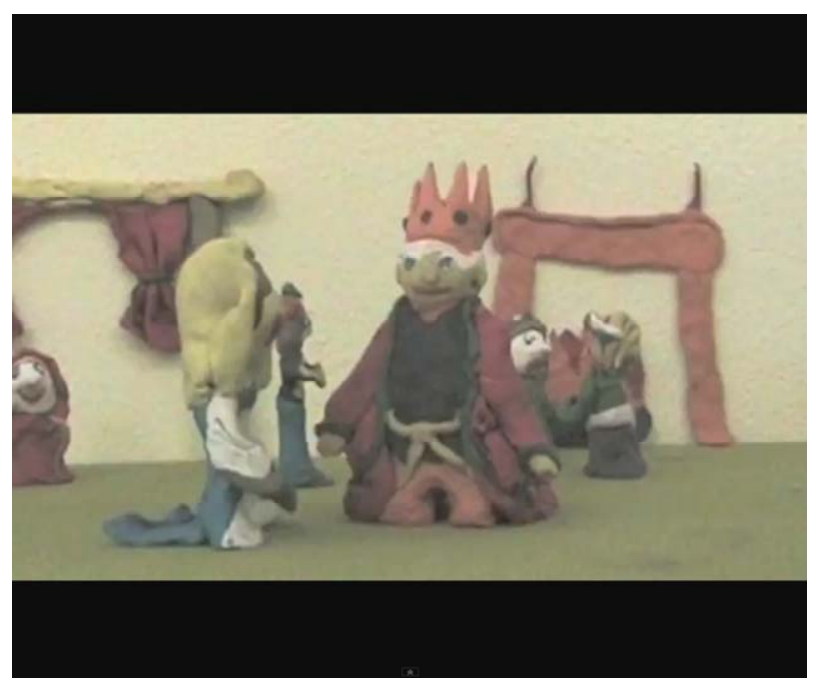

Figure 2.

"I care not though I were to live but one day and one night, if only my fame and my deeds live after me”: LS3 intergenerational animation project illustrating a scene from the heroic tales of Fionn mac Cumhaill and the warrior Fianna.

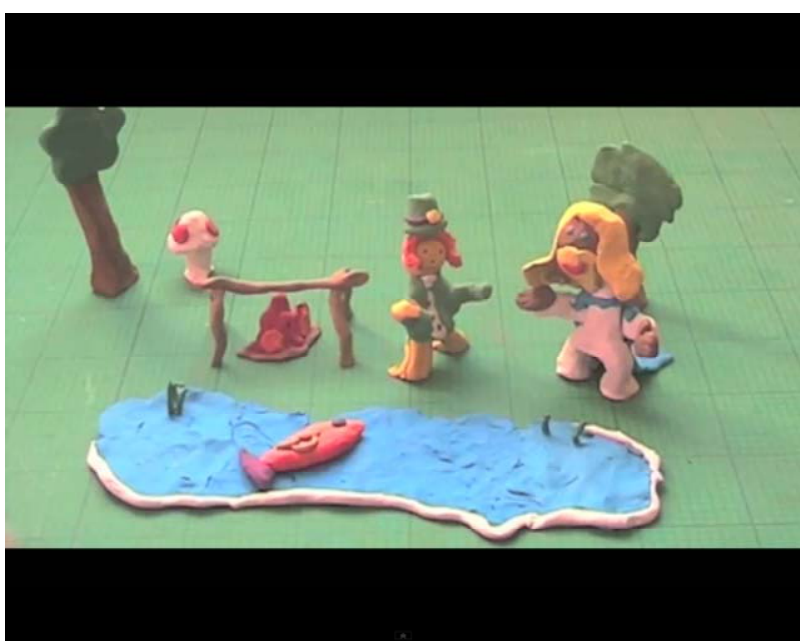

Figure 3.

"The salmon of knowledge" scene from an LS3 animation project.

The synergy of narrative and technology afforded a context in the LS3 project for learners of different ages to collaborate creatively in the development of the animation of Fionn and the Fianna. The animation technology in LS3 is eminently easy-touse. This creative stop-frame technology simply entails learners taking individual still images of an object, moving the object(s) while keeping the digital camera in a fixed position, and subsequently piecing the images together-as seamlessly as possible-into a coherent narrative sequence. There is bespoke animation software. In our narrative technology, we generally utilise Kudlian Software's I Can Animate. This software is now available — and works very elegantly_in app format for mobile and ultra-portable devices, e.g. iPad, iPhone. The role of artists and writers in the process also enhanced the editing and scripting process. The intergenerational groups worked interactively together to design and produce their animations. They developed collaboratively and creatively characters/figurines from plasticine; coordinated the movement and animation of their small figures, representing the key protagonists in the story; recorded voiceovers for narrator and dialogue between characters; and selected and integrated appropriate music and sound effects.

A further example of narrative technology as pedagogical methodology is the use of animation tools by teachers to enhance their teaching of their respective subject specialism and area of the curriculum. Figures $\mathbf{4}$ and $\mathbf{5}$ illustrate pre-service mathematics teachers developing animations to embody and explain mathematical concepts. As a narrative technology, animation (stopframe animation) can be particularly powerful in supporting alternative, creative and novel interpretations of the curriculum. In a sense, the role of the teacher in the classroom-in communicating their subject to their pupils-is that of an animator. The teacher must imbue their subject with life; make it sentient and interesting for pupils. Animation can thus help to develop teachers' capacity to engage creatively with their subject and specialist area of the curriculum, exploring creative ways to communicate a topic(s) engagingly to their pupils.

\section{Narrative Technology for Reflection}

In addition to supporting creative engagement with the curriculum, collaborative learning and intergenerational education, our other deployments of narrative technology have included 


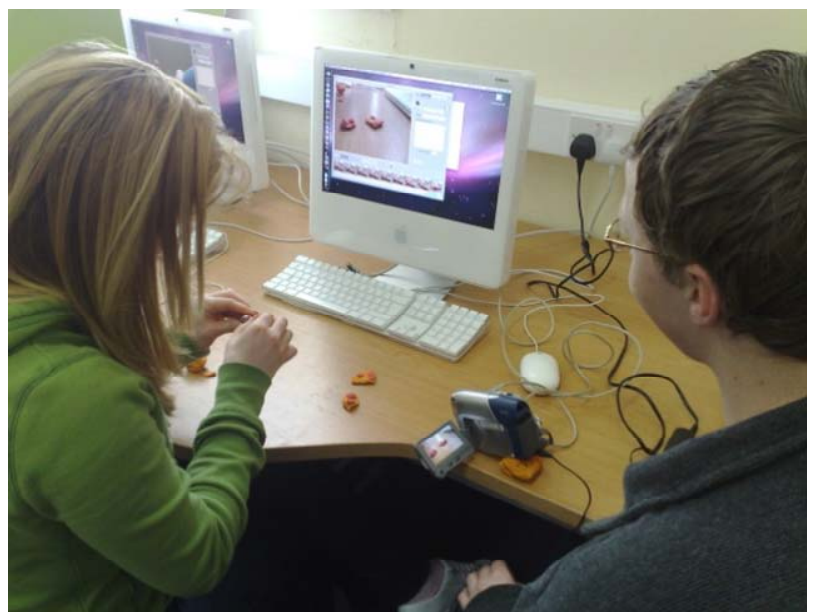

Figure 4.

Mathematics education students developing an animation to teach fractions.

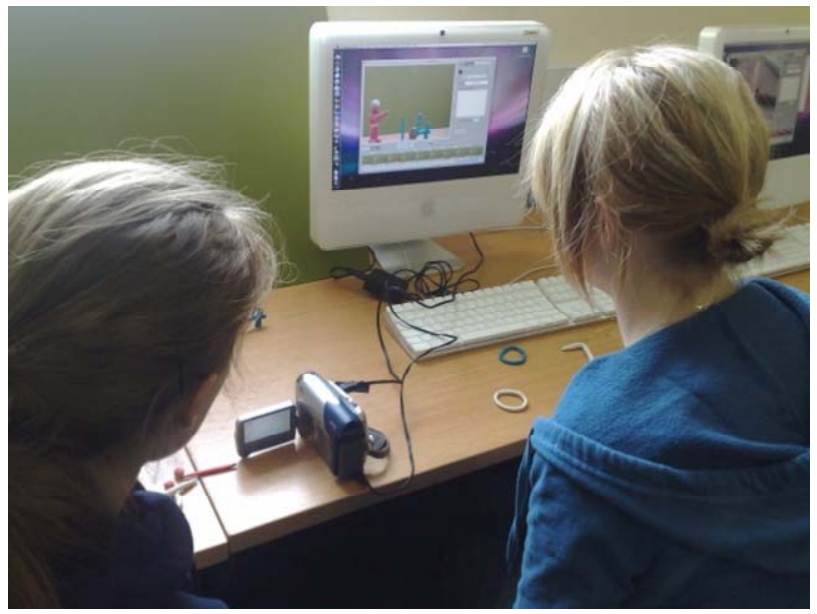

Figure 5.

Mathematics education students developing an animation to teach the decimal system.

focusing on the development of critical reflection and professsional identity formation for teachers. The principal narrative technology we have used in this context is digital storytelling.

As with animation, digital storytelling is an eminently straightforward narrative technology to design, implement and use. There can be different genres of digital stories, but they are typically and simply sequences of images (ordinarily still images) accompanied by a voiceover, which narrates/tells a story. The images are selected for their representative or symbolic quality in supporting and amplifying the narration. The purpose of introducing digital storytelling was to try to enhance teachers' critical reflection, in order to support the development of their pro- fessional awareness and identity.

In our initial interventions with digital storytelling for teachers, the stories they designed and produced were generally of a descriptive nature. The teachers outlined their experiences as educators but the level of critical reflection and insight could be limited.

To enhance teachers' digital storytelling, in subsequent implementations and iterations, we introduced a literary device well-established in literature for over two thousand years, na- mely Aristotle’s concept of “peripeteia” from the Poetics (c. 335). In this development, we were inspired by Bruner (2007) and his application of Aristotelian, Formalist and psychological literary constructs and ideas to education, including the peripeteia or "twist in the tale". "According to Bruner (2007), the peripeteia introduces dramatic tension, excitement and "cultivates a lively sense of the possible' in education and life."

The peripeteia that was selected for the teachers' digital stories was that of the critical incident. A critical incident can be defined as a signally formative moment or experience in a professional's practice learning. It can be a negative or positive experience that affords insight respecting what it means to be a professional: teacher, lawyer, doctor etc. It has the potential to change fundamentally the professional's view of themselves and their profession. Since the introduction of the peripeteia of the critical incident as an orienting concept, the digital stories that teachers have created have demonstrated significant variety and, in general, tremendous insight. They have covered many salient issues and topics, ranging from bullying and addressing bullying in schools, to philosophical reflections on education and teaching, and images of teaching and teachers' professional identity in the $21^{\text {st }}$ Century. A key benefit of digital storytelling is its focus on acknowledging the critical incident or professional peripeteia as a moment of insight; to position it in terms of the life-story-see its meaning in the context of one's nöogenic narrative; and explain ultimately how it has effected personal-professional growth. The focus is not to dwell on the critical incident per se but to see in it potential for professional learning, development and enhancement. This positive-psychological approach - to see opportunities and solutions in challenges and problems - is a core aspect of modern professional education for teachers (e.g. Korthagen, 2011). "Productive Failure": harnessing the latent productivity in apparent failure is a potentially powerful contemporary development in education and educational design (Kapur, 2008). Digital narrative and storytelling can help to enhance significantly processes of professional awareness, reflection and development; in particular through the creative narrative re-imagining of challenges/problems as opportunities/solutions.

\section{Insights for Creative Education}

Narrative technology has the potential to enhance nöogenic narrative along the three interactive dimensions: accomplishment, affect and attitude. Bruner (2007) outlines how narrative can fulfil our "push for completion"- to structure, and make sense of experience. In evaluations of narrative technology, learners have reported their sense of accomplishment once they have created and finished their animations, digital narratives and stories. Narrative technology can help learners to make sense of what might otherwise be quite inscrutable or potentially unintelligible experience. For teachers, it has had significant positive impact upon their confidence to understand and improve upon their professional practice. The tensive capacity of narrative - to facilitate at the same time fixity and flexibility - can support learners in making sense of challenges and problems that can arise; however it enables them also to interpret creatively and address strategically those challenges/problems.

In the digital storytelling narrative technology, the focus is not on the critical incident per se but rather what can be learnt from the professional peripeteia to improve teaching practice. Also, where teachers implement changes or take action to im- 
prove practice, digital storytelling can continue to provide a technology-enhanced, meaningful context for critical reflection on, and creative interpretation of experience. The working positively towards a resolution or dénouement through narrative technology can help to effect attitudinal change in terms of developing teachers' confidence to be able to understand challenges and problems - and to be able to solve those problems creatively and productively. Narrative technology can significantly enhance accomplishment, affect and attitude by providing media rich, technology-enhanced contexts for creativity and creative education.

In the intergenerational project the synergy of narrative and technology supported collaborative creativity amongst learners of very different ages. The intergenerational teams worked together to interpret creatively heroic sagas and stories, which helped to break down age barriers and foster collaboration and meaningful interaction. The simplicity of the technology also ensured that all learners were involved in the development of the animated stories. A further, significant technical aspect of narrative technology is the high usability of the tools used, which helps to ensure the focus remains principally on learning and that all learners feel included/involved.

\section{Conclusion}

The synergy of storytelling and computing-what we term narrative technology - is creating possibilities for a digital renaissance in education. The ease-of-use of new and emerging storytelling technologies, synergised with the imaginative, potentially transformative human power of narrative is opening up new possibilities to enhance creativity and creative education. It is potentially enabling more learners to be creative with digital media-irrespective of their creativity or "lack" of creativity heretofore. It is potentially enhancing learners' engagement with technology-irrespective of possible limitations in their historical or prior use of ICT. Narrative technology is creating potential for a renaissance in education and educational technology-across the dynamic, interactive dimensions of nöogenic narrative-with significant positive impacts for learner accomplishment, affect and attitude.

\section{Acknowledgements}

Firstly, the author wishes to thank colleagues and students of the School of Education, National University of Ireland, Galway, and in particular: Prof. Chris Curtin, Bonnie Long, Jim Lenaghan, and Dr. Dolores Stewart. The author would furthermore like to thank the Dean and the College of Arts, Social Sciences and Celtic Studies, NUI Galway; Apple Education; and Galmac for their support of the research reported in this paper-through the School of Education's Apple iPedagogy Learning Environment (AiPLE), Apple Regional Training Cen- tre. The author also wishes to thank colleagues in the BEAM Consortium, Building European Identity through Spirit, Sense and Meaning, and Hewlett Packard (Innovation in Education Award 2009) for their support of the research reported here.

\section{REFERENCES}

Aristotle. (c.335 BC/2007) Poetics. US: Forgotten Books.

Bruner, J. (1990). Acts of meaning. Cambridge, MA: Harvard University Press.

Bruner, J. (2002). Making stories: Law, literature, life. New York: Farrar Straus \& Giroux.

Bruner, J. (2007). Cultivating the possible. URL (last checked 16 November 2011)

http://www.education.ox.ac.uk/about-us/video-archive/

Cuban, L. (2001). Oversold and underused: Computers in the classroom. Cambridge, MA: Harvard University Press.

EU Kids Online. (2011). EU kids online final report. URL (last checked 28 September 2011).

http://www2.lse.ac.uk/media@lse/research/EUKidsOnline/Home.aspx

Frankl, V. E. (1946/2006). Man's search for meaning. UK: Beacon Press.

Futurelab. (2010). Digital Literacy Professional Development Resource. URL (last checked 26 September 2011).

http://www.futurelab.org.uk/sites/default/files/Digital_Literacy_Reso urce.pdf

Futurelab. (2010). Digital literacy across the curriculum. URL (last checked 26 September 2011).

http://www.futurelab.org.uk/sites/default/files/Digital_Literacy_hand book_0.pdf

Hall, T., Duignan, S., \& Long, B. T. (2011). Quality through synergy: Technology-enhanced learning (animation, virtualisation and multiuser virtual environments (MUVEs) in higher education. In T. Hourigan, L. Murray, \& E. Riordan, (Eds.), Quality issues in ICT integration: Third level disciplines and learning contexts (pp. 28-46). Newcastle upon Tyne: Cambridge Scholars Publishing.

Kapur, M. (2008). Productive failure. Cognition and Instruction, 26 , 379-424. doi:10.1080/07370000802212669

Korthagen, F. (2011). Moving from the inside out: Connecting practice, theory, and person. International Association of Physical Education in Higher Education 2011 Conference, Limerick, 22-25 June 2011.

Pearse, P. H. (1916/2010). The murder machine. URL (last checked 6 November 2011).

http://www.ucc.ie/celt/published/E900007-001/index.html

Plowman, L., \& Stephen, C. (2003). A “benign addition”? A review of research on ICT and pre-school children. Journal of Computer-Assisted Learning, 19, 149-164. doi:10.1046/j.0266-4909.2003.00016.x

Rizza, C. (2011). ICT and initial teacher education: National policies OECD Education Working Papers, 61, 55. doi:10.1787/5kg57kjj5hs8-en

Schank, R. (1990). Tell me a story: Narrative and intelligence. Evanston: Northwestern University Press.

Seligman, M. E. P. (2011). Flourish: A visionary new understanding of happiness and well-being. New York: Free Press.

Strawson, G. (2004). Against narrativity. Ratio, 17, 428-452. doi:10.1111/j.1467-9329.2004.00264.x 